\title{
Proton-detected 3D ${ }^{1} \mathrm{H} /{ }^{13} \mathrm{C} /{ }^{1} \mathrm{H}$ correlation experiment for structural analysis in rigid solids under ultrafast-MAS above $60 \mathrm{kHz}$
}

\author{
Rongchun Zhang, ${ }^{1}$ Yusuke Nishiyama, ${ }^{2,3}$ and Ayyalusamy Ramamoorthy ${ }^{1, a)}$ \\ ${ }^{1}$ Biophysics and Department of Chemistry, The University of Michigan, Ann Arbor, Michigan 48109-1055, USA \\ ${ }^{2}$ JEOL RESONANCE Inc., Musashino, Akishima, Tokyo 196-8558, Japan \\ ${ }^{3}$ RIKEN CLST-JEOL Collaboration Center, RIKEN, Yokohama, Kanagawa 230-0045, Japan
}

(Received 1 August 2015; accepted 6 October 2015; published online 22 October 2015)

\begin{abstract}
A proton-detected 3D ${ }^{1} \mathrm{H} /{ }^{13} \mathrm{C} /{ }^{1} \mathrm{H}$ chemical shift correlation experiment is proposed for the assignment of chemical shift resonances, identification of ${ }^{13} \mathrm{C}-{ }^{1} \mathrm{H}$ connectivities, and proximities of ${ }^{13} \mathrm{C}-{ }^{1} \mathrm{H}$ and ${ }^{1} \mathrm{H}^{-1} \mathrm{H}$ nuclei under ultrafast magic-angle-spinning (ultrafast-MAS) conditions. Ultrafast-MAS is used to suppress all anisotropic interactions including ${ }^{1} \mathrm{H}-{ }^{1} \mathrm{H}$ dipolar couplings, while the finite-pulse radio frequency driven dipolar recoupling (fp-RFDR) pulse sequence is used to recouple dipolar couplings among protons and the insensitive nuclei enhanced by polarization transfer technique is used to transfer magnetization between heteronuclear spins. The 3D experiment eliminates signals from non-carbon-bonded protons and non-proton-bonded carbons to enhance spectral resolution. The $2 \mathrm{D}(\mathrm{F} 1 / \mathrm{F} 3)^{1} \mathrm{H} /{ }^{1} \mathrm{H}$ and $2 \mathrm{D}{ }^{13} \mathrm{C} /{ }^{1} \mathrm{H}(\mathrm{F} 2 / \mathrm{F} 3)$ chemical shift correlation spectra extracted from the 3D spectrum enable the identification of ${ }^{1} \mathrm{H}-{ }^{1} \mathrm{H}$ proximity and ${ }^{13} \mathrm{C}-{ }^{1} \mathrm{H}$ connectivity. In addition, the $2 \mathrm{D}(\mathrm{F} 1 / \mathrm{F} 2){ }^{1} \mathrm{H} /{ }^{13} \mathrm{C}$ chemical shift correlation spectrum, incorporated with proton magnetization exchange via the fp-RFDR recoupling of ${ }^{1} \mathrm{H}-{ }^{1} \mathrm{H}$ dipolar couplings, enables the measurement of proximities between ${ }^{13} \mathrm{C}$ and even the remote non-carbon-bonded protons. The $3 \mathrm{D}$ experiment also gives three-spin proximities of ${ }^{1} \mathrm{H}-{ }^{1} \mathrm{H}-{ }^{13} \mathrm{C}$ chains. Experimental results obtained from powder samples of L-alanine and L-histidine $\cdot \mathrm{H}_{2} \mathrm{O} \cdot \mathrm{HCl}$ demonstrate the efficiency of the 3D experiment. (C) 2015 AIP Publishing LLC. [http://dx.doi.org/10.1063/1.4933373]
\end{abstract}

\section{INTRODUCTION}

Although solid-state NMR has become a valuable technique in providing atomic-resolution structural and dynamic insights into a variety of non-crystalline and non-soluble molecular systems, ${ }^{1-9}$ its poor sensitivity and demand for a large sample quantity continue to restrict its widespread applications. ${ }^{10}$ However, with the remarkable improvements in proton spectral resolution enabled by recent developments in ultrafast-MAS technology, sensitivity related difficulties are largely overcome by utilizing the advantages of very high abundance and large gyromagnetic ratio of protons by proton detection. ${ }^{11}$ Indeed, proton-detected NMR methodology has become an attractive avenue in the development of multidimensional solid-state NMR spectroscopy. ${ }^{12-24}$ Ultrafast magic-angle-spinning (Ultrafast-MAS) has also enabled the use of low power radio frequency (RF) fields for crosspolarization (CP) and heteronuclear decoupling, ${ }^{25-31}$ which are significant benefits for solid-state NMR studies on heatsensitive samples and also for experiments requiring long mixing or decoupling periods.

One of the most commonly used NMR-based structural studies strategy employs internuclear correlations, which are easily obtained from homonuclear or heteronuclear multidimensional NMR experiments. While two-dimensional correlation experiments provide two-spin correlations, higher dimen-

\footnotetext{
a) Author to whom correspondence should be addressed. Electronic mail: ramamoor@umich.edu
}

sional NMR experiments can give insights into more complex spin connectivities/proximities. The nuclear spin connectivity/proximity can be achieved via either through-space (using NOE or coherent dipolar coupling) or through-bond (using scalar or $J$ coupling) depending on the magnetization transfer process used in the correlation experiments. Although, because of the strong ${ }^{1} \mathrm{H}^{-1} \mathrm{H}$ dipolar coupling networks, ${ }^{1} \mathrm{H} /{ }^{1} \mathrm{H}$ connectivity/proximity is mostly obtained via throughspace interactions in solids, heteronuclear connectivity can be obtained via either through-bond or through-space interactions using the insensitive nuclei enhanced by polarization transfer (INEPT).

Among all the approaches used for heteronuclear polarization transfer, the INEPT experiment is commonly used for signal enhancement of low- $\gamma$ nuclei in solution NMR spectroscopy. ${ }^{32,33}$ On the other hand, the presence of strong ${ }^{1} \mathrm{H}^{-1} \mathrm{H}$ dipolar couplings in solids results in a fast decay of magnetization due to a short spin-spin relaxation time $\left(T_{2}\right)$, and therefore the inefficiency of magnetization transfer via $J$ couplings in solids. To overcome this difficulty, homonuclear ${ }^{1} \mathrm{H}-{ }^{1} \mathrm{H}$ decoupling pulse sequences, such as frequency-switched Lee-Goldburg (FSLG), ${ }^{34,35}$ PMLG (phase-modulated LeeGoldburg), ${ }^{36}$ or DUMBO (decoupling using mind-boggling optimization), ${ }^{37,38}$ are employed in the evolution periods of INEPT $^{39-41}$ to enable $J$ coupling based transfer of magnetization. Interestingly, it was recently demonstrated that the heteronuclear polarization transfer occurs mainly through dipolar couplings instead of $J$ coupling under ultrafastMAS, ${ }^{42,43}$ where the premise for the polarization transfer is 
the simultaneous presence of ${ }^{1} \mathrm{H}-{ }^{1} \mathrm{H}$ homonuclear and ${ }^{13} \mathrm{C}-{ }^{1} \mathrm{H}$ heteronuclear dipolar couplings. It has been demonstrated that the quaternary ${ }^{13} \mathrm{C}$ magnetization can be suppressed, due to weak non-bonded ${ }^{13} \mathrm{C}^{-1} \mathrm{H}$ dipolar couplings and absence of nearby ${ }^{1} \mathrm{H}-{ }^{1} \mathrm{H}$ dipolar couplings, when INEPT is used for ${ }^{1} \mathrm{H} \rightarrow{ }^{13} \mathrm{C}$ polarization transfer under ultrafast-MAS. ${ }^{43}$ Therefore, it is possible to obtain a ${ }^{13} \mathrm{C} /{ }^{1} \mathrm{H}$ heteronuclear chemical shift correlation (HETCOR) spectrum only for the directly ${ }^{1} \mathrm{H}^{13} \mathrm{C}$ bonded pairs of nuclei in solids by INEPT based ${ }^{1} \mathrm{H} \rightarrow{ }^{13} \mathrm{C}$ polarization transfer as demonstrated in the literature, ${ }^{42}$ although the polarization transfer is primarily due to unaveraged dipolar couplings present in solids.

In this study, we propose a proton-detected 3D pulse sequence (Fig. 1) that combines a finite-pulse radio frequency driven dipolar recoupling (fp-RFDR) ${ }^{44-47}$ and an INEPT-based polarization transfer to obtain three-spin isotropic chemical shift correlation of ${ }^{1} \mathrm{H}$ and ${ }^{13} \mathrm{C}$ nuclei under ultrafast-MAS conditions. In spite of a very small sample quantity used in ultrafast-MAS experiments, higher sensitivity rendered by ${ }^{1} \mathrm{H}$ detection enables 3D experiments to be completed within a reasonable time, and the higher dimension gives additional resolution enhancement. For simplicity, we refer this 3D fp-RFDR incorporated INEPT-based heteronuclear single-quantum correlation (HSQC) experiment as RFDRHSQC. From this 3D RFDR-HSQC experiment, 2D ${ }^{1} \mathrm{H} /{ }^{1} \mathrm{H}$ $(\mathrm{F} 1 / \mathrm{F} 3)$ and $2 \mathrm{D}{ }^{13} \mathrm{C} /{ }^{1} \mathrm{H}(\mathrm{F} 2 / \mathrm{F} 3)$ chemical shift correlation spectra can be easily extracted for chemical shift resonance assignments. More importantly, the $2 \mathrm{D}{ }^{1} \mathrm{H} /{ }^{13} \mathrm{C}(\mathrm{F} 1 / \mathrm{F} 2)$ chemical shift correlation spectrum, mediated by ${ }^{1} \mathrm{H}-{ }^{1} \mathrm{H}$ magnetization exchange via the fp-RFDR-recoupled dipolar couplings among protons, could be used to determine the proximities of non-bonded ${ }^{13} \mathrm{C}$ and ${ }^{1} \mathrm{H}$ nuclei. The $3 \mathrm{D}$
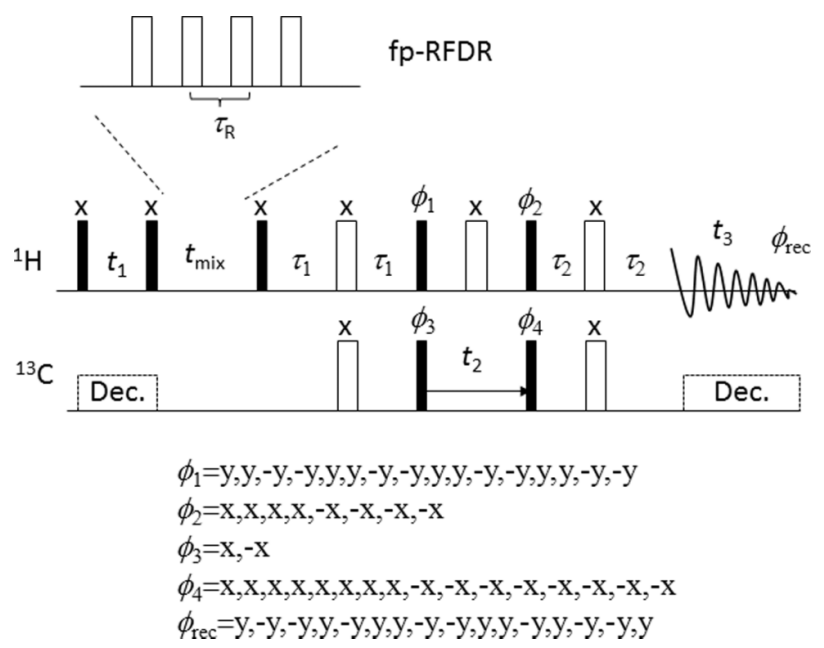

FIG. 1. Pulse sequence for the 3D RFDR-HSQC ${ }^{1} \mathrm{H} /{ }^{13} \mathrm{C} /{ }^{1} \mathrm{H}$ chemical shift correlation experiment. Solid and blank rectangles represent the $90^{\circ}$ and $180^{\circ}$ pulses, respectively. Finite-pulse-RFDR with an $\mathrm{XY} 4^{1}{ }_{4}$ phase cycling $(X Y X Y Y \bar{X} Y \bar{X} \overline{X Y X Y} \bar{Y} X \bar{Y} X)$ is used for ${ }^{1} \mathrm{H}^{-1} \mathrm{H}$ dipolar recoupling under ultrafast-MAS. INEPT-based HSQC pulse sequence is used for ${ }^{1} \mathrm{H} \rightarrow{ }^{13} \mathrm{C}$ and ${ }^{13} \mathrm{C} \rightarrow{ }^{1} \mathrm{H}$ magnetization transfers as well as to enable ${ }^{13} \mathrm{C}$ chemical shift evolution. Phase cyclings used for RF pulses in the sequence and the receiver are given at the bottom. Low RF power continuous-wave ${ }^{13} \mathrm{C}$ heteronuclear decoupling could also be used during the $t_{1}$ and $t_{3}$ periods or ${ }^{1} \mathrm{H}$ heteronuclear decoupling during the $t_{2}$ period to obtain a better spectral resolution if necessary. experiment also gives significant insights into the ${ }^{1} \mathrm{H}-{ }^{1} \mathrm{H}^{-13} \mathrm{C}$ three-spin correlations/proximities. As demonstrated by the experimental results, the use of INEPT suppresses noncarbon-bonded ${ }^{1} \mathrm{H}$ resonances and thus enhances the spectral resolution. The sensitivity enhancement rendered by protondetection ${ }^{11,15}$ significantly reduces the measurement time of the $3 \mathrm{D}{ }^{1} \mathrm{H} /{ }^{13} \mathrm{C} /{ }^{1} \mathrm{H}$ chemical shift correlation experiment.

\section{EXPERIMENTAL}

\section{Samples}

Uniformly ${ }^{13} \mathrm{C},{ }^{15} \mathrm{~N}$-labeled L-alanine was purchased from Isotec (Champaign, IL) and uniformly ${ }^{13} \mathrm{C},{ }^{15} \mathrm{~N}$-labeled L-histidine $\cdot \mathrm{HCl} \cdot \mathrm{H}_{2} \mathrm{O}$ was bought from Acros Organics (Morris Plains, NJ). All samples were used as received without any further purification.

\section{Solid-state NMR}

The 3D RFDR-HSQC pulse sequence along with phase cyclings is shown in Fig. 1. First, the ${ }^{1} \mathrm{H}$ magnetization is prepared in the transverse plane for isotropic chemical shift evolution during the $t_{1}$ period, and then it is flipped to the $z$-axis for magnetization exchange through the recoupled ${ }^{1} \mathrm{H}-{ }^{1} \mathrm{H}$ dipolar couplings during fp-RFDR. After fp-RFDR, the transverse ${ }^{1} \mathrm{H}$ magnetization is transferred to ${ }^{13} \mathrm{C}$ through the INEPT sequence. After ${ }^{13} \mathrm{C}$ chemical shift evolution during the $t_{2}$ period, the ${ }^{13} \mathrm{C}$ magnetization is transferred back to ${ }^{1} \mathrm{H}$ for detection using INEPT-based sequence. 3D experiments on uniformly ${ }^{13} \mathrm{C},{ }^{15} \mathrm{~N}$ labeled L-alanine and Lhistidine $\cdot \mathrm{HCl} \cdot \mathrm{H}_{2} \mathrm{O}$ were performed using an Agilent/Varian VNMRS $600 \mathrm{MHz}$ solid-state NMR spectrometer operating at $599.8 \mathrm{MHz}$ for ${ }^{1} \mathrm{H}$ and $150.8 \mathrm{MHz}$ for ${ }^{13} \mathrm{C}$ nuclei, respectively, and a $1.2 \mathrm{~mm}$ HXY triple-resonance MAS probe. The spinning speed of the sample was $60 \mathrm{kHz}$ MAS. The $90^{\circ}$ pulse lengths were $1.4 \mu$ s for both ${ }^{13} \mathrm{C}$ and ${ }^{1} \mathrm{H}$ nuclei. $16 t_{1}$ and $36 t_{2}$ increments with 16 scans were used to acquire $3 \mathrm{D}$ spectra. $\mathrm{XY} 4{ }^{1}{ }_{4}$ phase cycling scheme was used for fp-RFDR, which has been demonstrated to provide the best performance for recoupling ${ }^{1} \mathrm{H}-{ }^{1} \mathrm{H}$ dipolar couplings under ultrafast-MAS and overcoming the effects of chemical shift offset and RF field inhomogeneity. ${ }^{45,46}$ For comparison, a regular $2 \mathrm{D}{ }^{1} \mathrm{H} /{ }^{1} \mathrm{H}$ correlation experiment ${ }^{45,46}$ was also performed on both alanine and histidine samples, where a total proton correlation was achieved using a fp-RFDR mixing time of $1 \mathrm{~ms}$ and $3 \mathrm{~ms}$, respectively.

\section{RESULTS AND DISCUSSION}

The performance of the 3D RFDR-HSQC pulse sequence is demonstrated on uniformly ${ }^{13} \mathrm{C},{ }^{15} \mathrm{~N}$ labeled L-alanine and uniformly ${ }^{13} \mathrm{C},{ }^{15} \mathrm{~N}$-labeled L-histidine $\cdot \mathrm{HCl} \cdot \mathrm{H}_{2} \mathrm{O}$ powder samples using 600 NMR spectrometers and at spinning speeds of $60 \mathrm{kHz}$ and above. The 3D experimental results are presented as 2D spectra (obtained through skyline projection) in Figs. 2 and 3 for L-alanine and in Figs. 4-7 for L-histidine $\cdot \mathrm{HCl} \cdot \mathrm{H}_{2} \mathrm{O}$. 

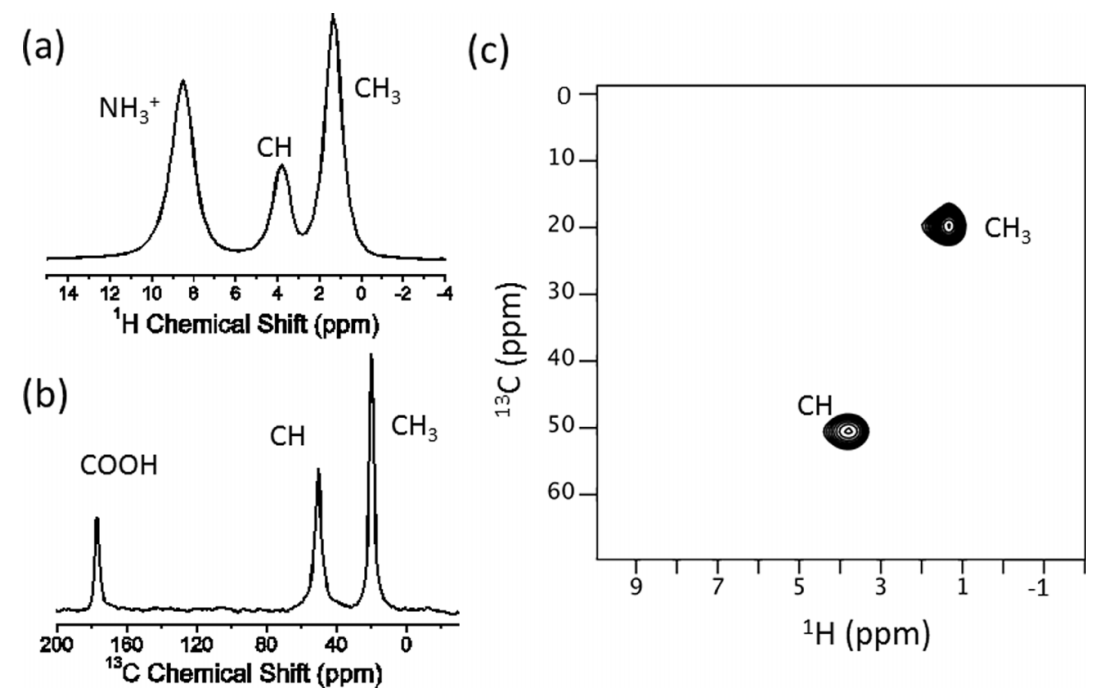

FIG. 2. 1D and 2D NMR spectra of $\mathrm{U}^{13} \mathrm{C}^{15}{ }^{15} \mathrm{~N}-\mathrm{L}$-alanine under $60 \mathrm{kHz}$ MAS. (a) A single pulse proton spectrum. (b) ${ }^{13} \mathrm{C}$ CPMAS spectrum obtained with double quantum $\mathrm{CP}^{28}$ (c) $2 \mathrm{D}{ }^{13} \mathrm{C} /{ }^{1} \mathrm{H}$ correlation spectrum (F2/F3) extracted from the 3D RFDRHSQC spectrum that was obtained using a fp-RFDR mixing time of $1 \mathrm{~ms}, 16$ $t_{1}, 36 t_{2}$, and 16 scans. In the INEPT sequence of the $3 \mathrm{D}$ experiment, the evolution delays $\left(\tau_{1}\right.$ and $\left.\tau_{2}\right)$ were both set to $0.5 \mathrm{~ms}$.

\section{D RFDR-HSQC suppresses non-carbon-bonded ${ }^{1} \mathrm{H}$ resonances}

Although faster spinning speed (up to $110 \mathrm{kHz}$ ) has been shown to effectively suppress ${ }^{1} \mathrm{H}-{ }^{1} \mathrm{H}$ dipolar couplings and enable proton-detected multidimensional experiments with reasonably well-resolved proton spectral lines, ${ }^{48-51}$ there is a need for approaches to further enhance the spectral resolution. There are two ways to achieve higher spectral resolution. One way is to further reduce the linewidth and the other way is to make the spectrum less crowded by filtering or higher dimensional experiments. In spite of the contributions from ultrafast-MAS to the former mechanism, the observed spectral resolution in solids is rather limited compared to that in solution. Line-broadening from anisotropic-bulk magnetic-susceptibility ${ }^{52}$ and conformational heterogeneity cannot be suppressed even at infinite MAS rate. On the other hand, ultrafast-MAS enables the use of the latter approach, i.e., higher dimensionality, thanks to the higher sensitivity rendered by ${ }^{1} \mathrm{H}$ detection. The involvement of low- $\gamma$ nuclei is an obvious way to resolve the overlapping proton peaks in a $2 \mathrm{D}{ }^{1} \mathrm{H} /{ }^{1} \mathrm{H}$ correlation spectrum as demonstrated in the recently reported $3 \mathrm{D}$ proton-detected ultrafast-MAS NMR experiments. ${ }^{20,53-55}$ In addition, the use of spectral editing can (a)
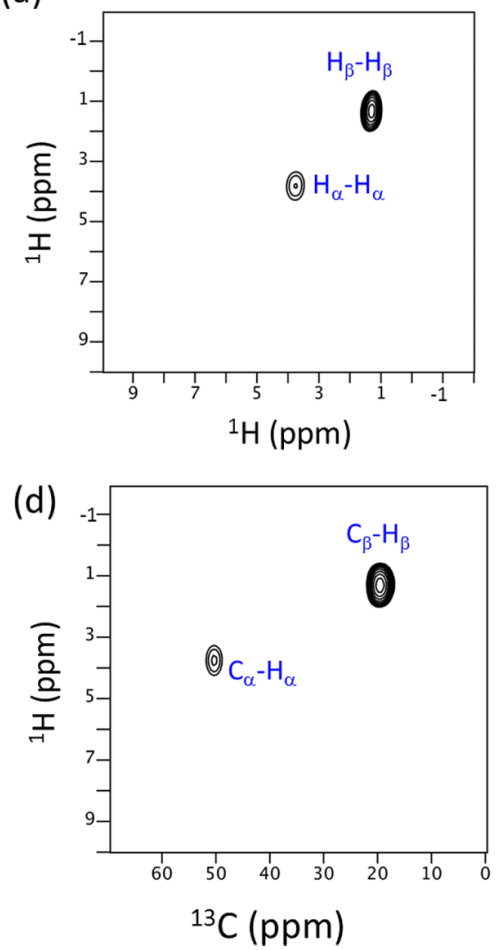

(b)

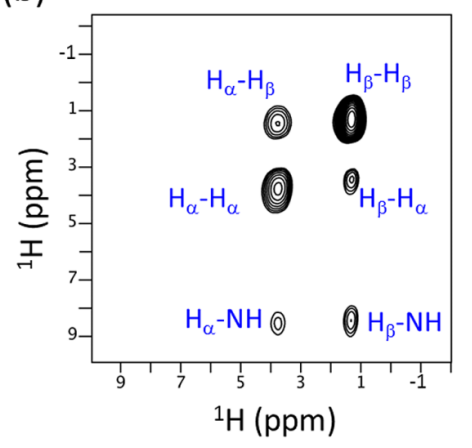

(e)

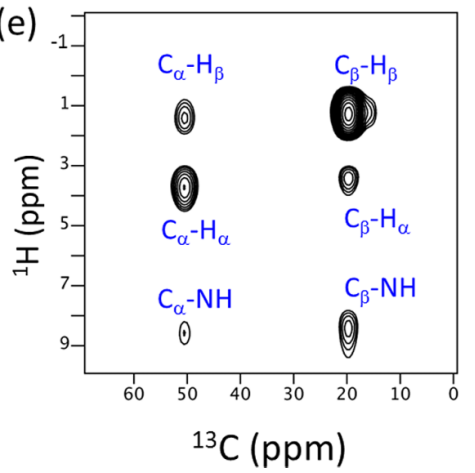

(c)

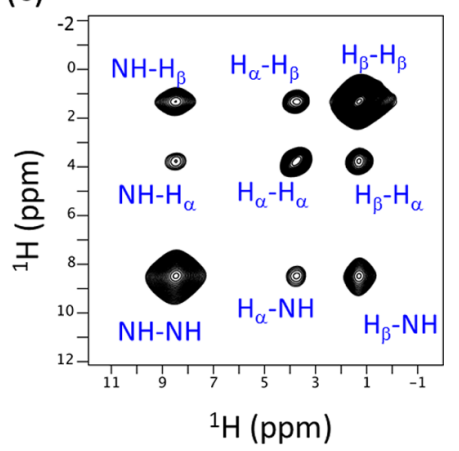

FIG. 3. $2 \mathrm{D}{ }^{1} \mathrm{H} /{ }^{1} \mathrm{H}$ homonuclear correlation and ${ }^{13} \mathrm{C} /{ }^{1} \mathrm{H}$ heteronuclear correlation spectra. ((a) and (b)) $2 \mathrm{D}{ }^{1} \mathrm{H} /{ }^{1} \mathrm{H}(\mathrm{F} 1 / \mathrm{F} 3)$ homonuclear correlation spectra extracted from the 3D spectra that were obtained without (a) or with (b) fp-RFDR during the mixing time. (c) A regular $2 \mathrm{D}{ }^{1} \mathrm{H} /{ }^{1} \mathrm{H}$ fp-RFDR correlation spectrum. ((d) and (e)) 2D fp-RFDR mediated ${ }^{1} \mathrm{H} /{ }^{13} \mathrm{C}(\mathrm{F} 1 / \mathrm{F} 2)$ correlation spectra extracted from the 3D spectra that were obtained without (d) or with (e) fp-RFDR during the mixing time. The fp-RFDR mixing time was $t_{\mathrm{mix}}=1 \mathrm{~ms}$, and the time delays in the INEPT sequence were $\tau_{1}=\tau_{2}=0.5 \mathrm{~ms}$. 


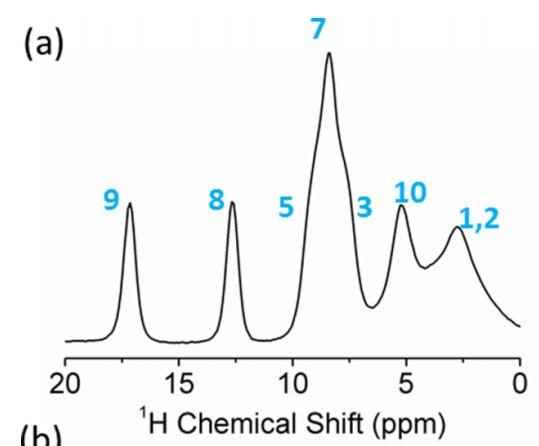

(b)

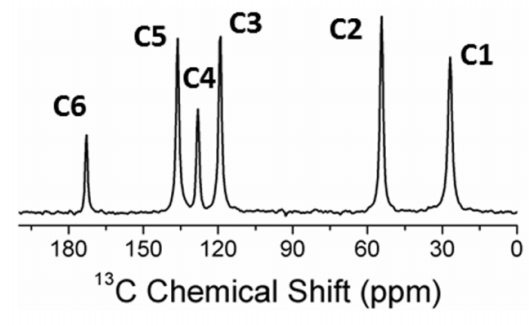

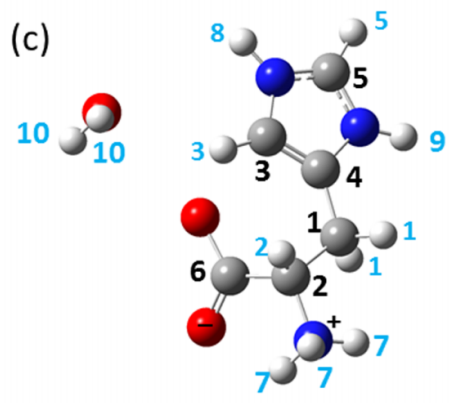

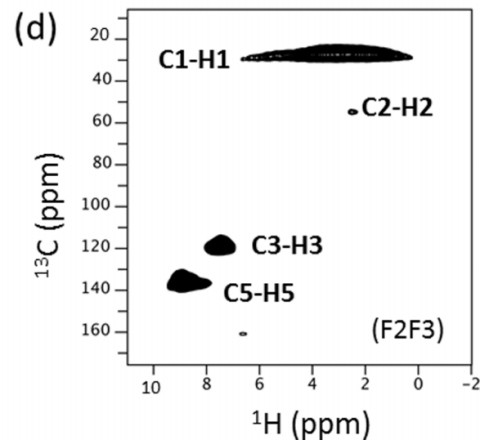

FIG. 4. $60 \mathrm{kHz}$ MAS $1 \mathrm{D}$ and 2D spectra of L-histidine $\cdot \mathrm{HCl} \cdot \mathrm{H}_{2} \mathrm{O}$. (a) A single pulse proton spectrum. (b) ${ }^{13} \mathrm{C}$ CPMAS spectrum obtained with double quantum $\mathrm{CP}^{28}$ (c) Schematic molecular structure of L-histidine $\cdot \mathrm{HCl} \cdot \mathrm{H}_{2} \mathrm{O}$. (d) $2 \mathrm{D}{ }^{13} \mathrm{C} /{ }^{1} \mathrm{H}$ chemical shift correlation spectrum (F2/F3) extracted from the 3D RFDR-HSQC spectrum that was acquired with a $3 \mathrm{~ms}$ fp-RFDR mixing time and using $0.15 \mathrm{~ms}$ for the $\tau_{1}$ and $\tau_{2}$ delays in INEPT. further enhance the spectral resolution as demonstrated by the 3D RFDR-HSQC pulse sequence. The magnetization transfer from ${ }^{1} \mathrm{H}$ to ${ }^{13} \mathrm{C}$ in $3 \mathrm{D}$ RFDR-HSQC can be used to selectively suppress certain resonances based on the magnitude of ${ }^{1} \mathrm{H}-{ }^{13} \mathrm{C}$ dipolar couplings, particularly the non-carbon-bonded proton resonances can be removed as demonstrated in this study. The $2 \mathrm{D}{ }^{13} \mathrm{C} /{ }^{1} \mathrm{H}(\mathrm{F} 2 / \mathrm{F} 3)$ spectrum, extracted from the $3 \mathrm{D}$ RFDR-HSQC spectrum, that correlates the chemical shifts of ${ }^{13} \mathrm{C}$ and ${ }^{1} \mathrm{H}$ nuclei is shown in Fig. 2(c). The $2 \mathrm{D}$ spectrum displays well-resolved $\mathrm{CH}$ and $\mathrm{CH}_{3}$ resonances from alanine while the non-carbon-bonded ${ }^{1} \mathrm{H}$ resonance from the $\mathrm{NH}_{3}^{+}$group is suppressed by using the INEPT sequence to transfer proton magnetization to carbon-13. Similarly, the nonhydrogen-bonded ${ }^{13} \mathrm{C}$ resonances can also be suppressed.

As demonstrated previously, ${ }^{42,43}$ the INEPT-based ${ }^{1} \mathrm{H}$ to ${ }^{13} \mathrm{C}$ polarization transfer under ultrafast-MAS requires the simultaneous presence of ${ }^{1} \mathrm{H}-{ }^{1} \mathrm{H}$ and ${ }^{13} \mathrm{C}-{ }^{1} \mathrm{H}$ dipolar couplings. As a result, the non-carbon-bonded ${ }^{1} \mathrm{H}$ and non-proton-bonded ${ }^{13} \mathrm{C}$ resonances are suppressed or extremely weak due to their weak ${ }^{13} \mathrm{C}-{ }^{1} \mathrm{H}$ dipolar couplings; the absence of nearby ${ }^{1} \mathrm{H}-{ }^{1} \mathrm{H}$ homonuclear dipolar couplings also assists the suppression of non-hydrogen-bonded ${ }^{13} \mathrm{C}$ resonances. It may be noted that a short contact time $(50 \sim 100 \mu \mathrm{s}) \mathrm{CP}$ can also avoid the nonbonded ${ }^{1} \mathrm{H}-{ }^{13} \mathrm{C}$ polarization transfer and could also be used instead of INEPT as their polarization transfer efficiencies are comparable. $^{42}$

\section{D RFDR-HSQC reveals the proximity of hydrogen and carbon atoms}

The 3D RFDR-HSQC experiment cannot only identify the bonded ${ }^{1} \mathrm{H}$ and ${ }^{13} \mathrm{C}$ nuclei as mentioned above but it can also be used to reveal the proximities between homonuclei (i.e., protons in this case) and heteronuclei (for example, ${ }^{1} \mathrm{H}$ and ${ }^{13} \mathrm{C}$ or ${ }^{1} \mathrm{H}$ and ${ }^{15} \mathrm{~N}$ nuclei). As demonstrated in this study, the homonuclear proximities can be obtained from the 2D ${ }^{1} \mathrm{H} /{ }^{1} \mathrm{H}(\mathrm{F} 1 / \mathrm{F} 3)$ spectrum extracted from the 3D RFDR-
HSQC spectrum, whereas the heteronuclei proximities can be determined from the $2 \mathrm{D}{ }^{13} \mathrm{C} /{ }^{1} \mathrm{H}(\mathrm{F} 1 / \mathrm{F} 2)$ chemical shift correlation. Obviously, the ${ }^{1} \mathrm{H} /{ }^{1} \mathrm{H}$ chemical shift correlation (F1/F3) spectrum provides information about ${ }^{1} \mathrm{H}-{ }^{1} \mathrm{H}$ proximity due to the magnetization exchange via the recoupled dipolar couplings among protons, which, in principle, is similar to the previously demonstrated 2D ${ }^{1} \mathrm{H} /{ }^{1} \mathrm{H}$ fp-RFDR chemical shift correlation experiment. ${ }^{45,46}$ However, the suppression of non-carbon-bonded protons and non-proton-bonded ${ }^{13} \mathrm{C}$ resonances can render higher resolution in the $3 \mathrm{D}$ RFDRHSQC spectrum as compared to the $2 \mathrm{D}{ }^{1} \mathrm{H} /{ }^{1} \mathrm{H}$ correlation spectrum. This is experimentally demonstrated as shown in Fig. 3. The 2D F1/F3 spectrum shows only diagonal peaks (self-correlation of resonances from chemically equivalent proton nuclei) corresponding to the aliphatic protons in the absence of RFDR (i.e., mixing time, $t_{\text {mix }}=0$ ) (Fig. 3(a)). But, when fp-RFDR is introduced in the mixing time, the magnetization exchange among protons results in cross peaks between proton resonances (Fig. 3(b)). However, due to the absence of non-carbon-bonded proton chemical shift evolution in the F3 dimension, the cross peaks between aliphatic and non-carbon-bonded protons only appear below the diagonal lines in the 2D F1/F3 spectrum (Fig. 3(b)), as compared to the regular $2 \mathrm{D}{ }^{1} \mathrm{H} /{ }^{1} \mathrm{H}$ chemical shift correlation spectrum shown in Fig. 3(c). Similarly, when $t_{\text {mix }}$ is zero, the 2D F1/F2 spectrum shown in Fig. 3(d) is exactly the same as the 2D F2/F3 spectrum, which directly provides the connectivity between ${ }^{13} \mathrm{C}$ and ${ }^{1} \mathrm{H}$ nuclei as discussed above. However, when fp-RFDR is introduced in the mixing time of the 3D experiment, cross peaks between carbon and remote protons are also observed as shown in Fig. 3(e). Indeed, the cross peaks between the ${ }^{13} \mathrm{CH}_{3}$ resonance and ${ }^{1} \mathrm{H}$ resonances of $\mathrm{CH}$ and $\mathrm{NH}_{3}^{+}$groups, and that between the ${ }^{13} \mathrm{CH}$ resonance and ${ }^{1} \mathrm{H}$ resonances of $\mathrm{CH}_{3}$ and $\mathrm{NH}_{3}^{+}$groups, resulted from the fp-RFDR enabled magnetization exchange among protons. Therefore, the $3 \mathrm{D}$ experiment can be potentially used to measure distance between a carbon and many protons and also between protons. 
(a)

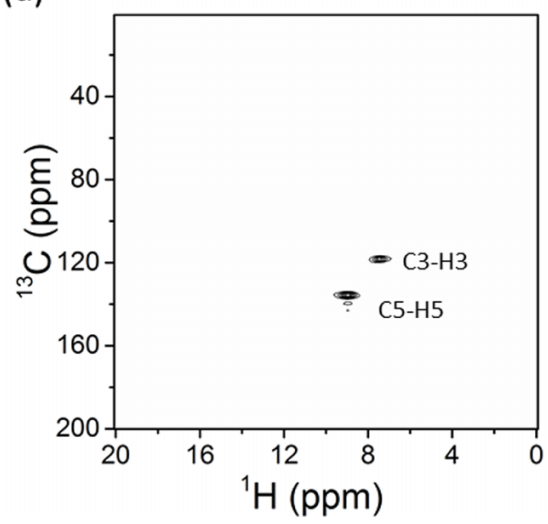

(b)

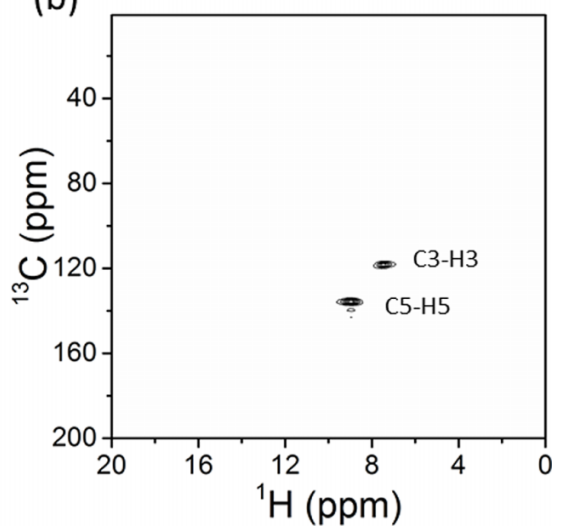

FIG. 5. 3D RFDR-HSQC spectrum of L-histidine $\cdot \mathrm{HCl} \cdot \mathrm{H}_{2} \mathrm{O}$. $2 \mathrm{D}{ }^{13} \mathrm{C} /{ }^{1} \mathrm{H}$ chemical shift correlation spectrum (F2/F3) extracted from the 3D RFDRHSQC spectrum that was acquired with a fp-RFDR mixing time of $0.457 \mathrm{~ms}$ (a) and $0.914 \mathrm{~ms}$ (b) and using $0.5 \mathrm{~ms}$ for $\tau_{1}$ and $\tau_{2}$ in INEPT. These two experiments were performed on a $600 \mathrm{MHz}$ JEOL ECZ600R solid-state NMR spectrometer using a $1.0 \mathrm{~mm}$ double-resonance ultrafast-MAS probe (JEOL RESONANCE, Inc.) at a spinning speed of $70 \mathrm{kHz}$.
More importantly, the 3D experimental results clearly give us a set of three spin ${ }^{1} \mathrm{H}^{-1} \mathrm{H}_{-}{ }^{13} \mathrm{C}$ proximities/correlations, where the ${ }^{1} \mathrm{H} /{ }^{1} \mathrm{H}$ correlation is determined by the fp-RFDR mixing time, and the ${ }^{1} \mathrm{H}_{-}{ }^{13} \mathrm{C}$ connectivity is provided by the INEPT-based polarization transfer.

\section{D RFDR-HSQC experiment on L-histidine $\cdot \mathrm{HCl} \cdot \mathrm{H}_{2} \mathrm{O}$}

The performance of the 3D RFDR-HSQC pulse sequence was further examined through experiments performed on a uniformly ${ }^{13} \mathrm{C},{ }^{15} \mathrm{~N}$-labeled L-histidine $\cdot \mathrm{HCl} \cdot \mathrm{H}_{2} \mathrm{O}$ powder sample. The ${ }^{1} \mathrm{H}$ and ${ }^{13} \mathrm{C}$ spectra under $60 \mathrm{kHz}$ MAS are shown in Fig. 4 along with the molecular structure of histidine $\cdot \mathrm{HCl} \cdot \mathrm{H}_{2} \mathrm{O}$. Similar to the spectrum of alanine (Fig. 2), the $2 \mathrm{D}{ }^{13} \mathrm{C} /{ }^{1} \mathrm{H}(\mathrm{F} 2 / \mathrm{F} 3)$ chemical shift correlation spectrum provides the ${ }^{13} \mathrm{C}-{ }^{1} \mathrm{H}$ bonding information. All the quaternary ${ }^{13} \mathrm{C}$ resonances and non-carbon-bonded ${ }^{1} \mathrm{H}$ resonances are absent in the $2 \mathrm{D}$ F2/F3 spectrum. It is also worth mentioning that the $\mathrm{C} 2-\mathrm{H} 2$ correlation peak is relatively weak compared to other peaks. This is because the $\mathrm{C}_{2} \mathrm{H}_{2}$ group experiences relatively a faster $T_{2}$ relaxation compared to nuclei in other chemical groups, which results in the fast decay and therefore the loss of transverse magnetization during INEPT.

In fact, the evolution delays were $150 \mu \mathrm{s} \quad\left(\tau_{1}=\tau_{2}\right.$ $=0.15 \mathrm{~ms}$ ) for the INEPT-based polarization transfer. When the evolution time was $500 \mu \mathrm{s}$, both $\mathrm{C} 1-\mathrm{H} 1$ and $\mathrm{C} 2-\mathrm{H} 2$ correlation peaks disappeared, as shown in Fig. 5, even though a short fp-RFDR mixing time was used $(0.457$ or $0.914 \mathrm{~ms})$. Therefore, it is very important to optimize the evolution time $\left(\tau_{1}\right.$ and $\left.\tau_{2}\right)$ periods in INEPT before performing the $3 \mathrm{D}$ experiment in order to achieve overall maximum polarization transfer efficiency, as was discussed in our previous work. ${ }^{43}$ If $T_{2}$ is too short and results in a significant loss of signal intensity, CP may be used as an alternative to INEPT for polarization transfer in the $3 \mathrm{D}$ experiment. However, the contact time of $\mathrm{CP}$ has to be sufficiently short to avoid the remote ${ }^{1} \mathrm{H}$ to ${ }^{13} \mathrm{C}$ polarization transfer, which is generally around $50 \mu$ s for a uniformly ${ }^{13} \mathrm{C}$-labeled polypeptides. ${ }^{56} \mathrm{On}$ the other hand, spectral editing is also possible by effectively utilizing the short $T_{2}$ of protons to eliminate resonances from certain chemical groups in rigid solids or from certain species in a heterogeneous mixture. It is worth noting that the $\mathrm{CP}$ contact-time for bonded ${ }^{1} \mathrm{H}_{-}{ }^{13} \mathrm{C}$ polarization transfer could be increased with further increasing the spinning speed due to better suppression of anisotropic ${ }^{1} \mathrm{H}-{ }^{1} \mathrm{H}$ dipolar couplings at higher spinning speeds. ${ }^{23}$ Besides, the ${ }^{13} \mathrm{C}$ and ${ }^{1} \mathrm{H}$ spinspin relaxation times increase significantly with the increasing spinning speed. Therefore, higher spinning speed (above $60 \mathrm{kHz}$ ) would weaken the $T_{2}$ relaxation and thus can improve the signal sensitivity. ${ }^{42,43,48}$

As mentioned above, the non-carbon-bonded proton signals can be greatly suppressed or removed by the INEPTbased polarization transfer. As shown in Fig. 6, after the twostep ${ }^{1} \mathrm{H} \rightarrow{ }^{13} \mathrm{C}$ and ${ }^{13} \mathrm{C} \rightarrow{ }^{1} \mathrm{H}$ polarization transfers through INEPT, all the non-carbon-bonded proton signals (such as H10 and H7) are completely removed whereas residual antiphase signals can be seen for $\mathrm{H} 9$ and $\mathrm{H} 8$. Such low intensity antiphase non-carbon-bonded proton signals were also observed in 1D ${ }^{13}$ C-detected INEPT experiments. ${ }^{42,43}$ However, these antiphase signals do not affect the results obtained in the $3 \mathrm{D}$ experiment, as they are completely removed when the $t_{1}$ and $t_{2}$ evolution times are not zero. Interestingly, the $\mathrm{H} 5$ and $\mathrm{H} 3$ peaks are very well resolved due to the complete removal of signals from $\mathrm{H} 7$ in the $1 \mathrm{D}$ spectrum obtained using the 3D RFDRHSQC pulse sequence by setting $t_{1}$ and $t_{2}$ to zero, whereas the peaks of $\mathrm{H} 5, \mathrm{H} 3$, and $\mathrm{H} 7$ protons are completely overlapped in a single pulse $1 \mathrm{D}^{1} \mathrm{H}$ spectrum as shown in Fig. 4(a). Therefore, these experimental results demonstrate that the 3D RFDRHSQC sequence can be used to resolve proton peaks that are overlapped with non-carbon-bonded proton peaks.

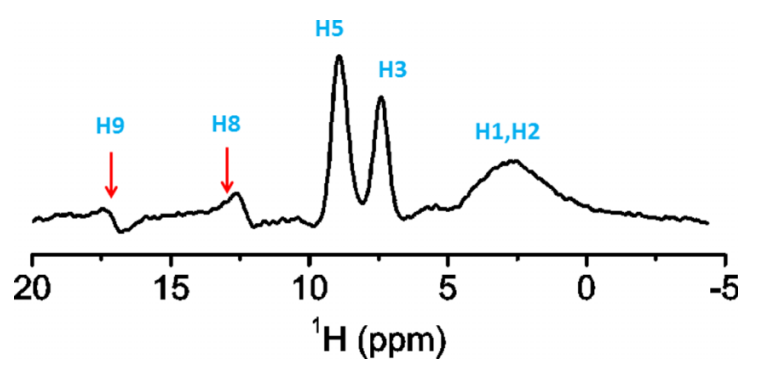

FIG. 6. 1D ${ }^{1} \mathrm{H}$ spectrum obtained using the $3 \mathrm{D}$ pulse sequence resolves the overlapping ${ }^{1} \mathrm{H}$ peaks. $60 \mathrm{kHz}$ MAS ${ }^{1} \mathrm{H}$ NMR spectrum of L-histidine $\cdot \mathrm{HCl} \cdot \mathrm{H}_{2} \mathrm{O}$ obtained using the 3D RFDR-HSQC sequence with $t_{1}=t_{2}=0$. All non-carbon-bonded proton peaks are filtered out or greatly suppressed. The red arrows indicate the residual antiphase signals from $\mathrm{H} 9$ and $\mathrm{H} 8$. 
(a)

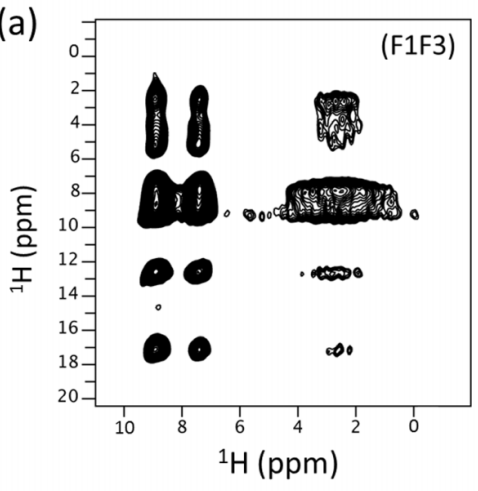

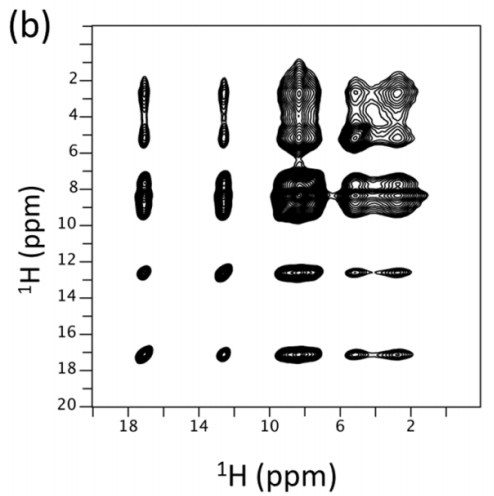

(c)

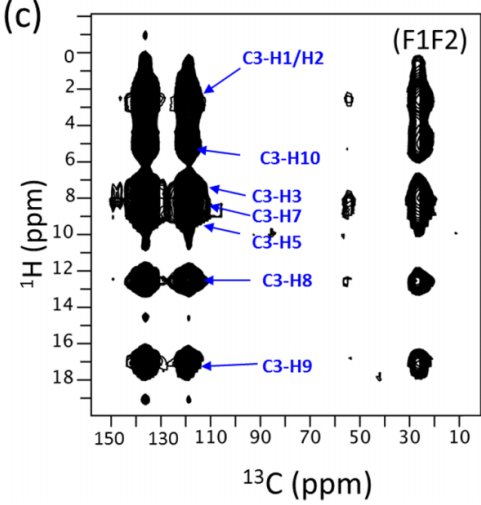

FIG. 7. Two-dimensional ${ }^{1} \mathrm{H} /{ }^{1} \mathrm{H}$ homonuclear correlation and ${ }^{13} \mathrm{C} /{ }^{1} \mathrm{H}$ heteronuclear correlation spectra. (a) $2 \mathrm{D}{ }^{1} \mathrm{H} /{ }^{1} \mathrm{H}$ chemical shift correlation spectra extracted from the 3D spectrum. (b) A regular $2 \mathrm{D} 1 \mathrm{H} / 1 \mathrm{H}$ correlation spectrum using fp-RFDR. (c) fp-RFDR mediated ${ }^{1} \mathrm{H} /{ }^{13} \mathrm{C}$ chemical shift correlation spectrum extracted from the $3 \mathrm{D}$ spectrum. A $3 \mathrm{~ms}$ fp-RFDR mixing time was used for all experiments. The cross peaks between C3 and other protons are indicated in blue.

The 2D F2/F3 $\left({ }^{13} \mathrm{C} /{ }^{1} \mathrm{H}\right)$, F1/F3 $\left({ }^{1} \mathrm{H} /{ }^{1} \mathrm{H}\right)$, and $\mathrm{F} 1 / \mathrm{F} 2$ $\left({ }^{1} \mathrm{H} /{ }^{13} \mathrm{C}\right)$ spectra extracted from the 3D spectrum further enable one to probe ${ }^{1} \mathrm{H}_{-}{ }^{1} \mathrm{H}$ and ${ }^{13} \mathrm{C}_{-}{ }^{1} \mathrm{H}$ proximities as shown in Fig. 7. Similar to the $2 \mathrm{D}{ }^{1} \mathrm{H} /{ }^{1} \mathrm{H}$ experiment, ${ }^{45,46}$ a $3 \mathrm{~ms}$ fp-RFDR mixing time is sufficient to accomplish a total correlation of all proton resonances as shown in Fig. 7(a). Even though the non-carbon-bonded proton resonances are completely removed in the final 3D spectrum, their chemical shift evolution is encoded in $t_{1}$ period before they are removed by the INEPT sequence. As a result, the cross peaks between aliphatic and all other protons could still be observed in the ${ }^{1} \mathrm{H} /{ }^{1} \mathrm{H}(\mathrm{F} 1 / \mathrm{F} 3)$ spectrum, although the spectral pattern is not symmetrical with respect to the diagonal (Fig. 7(a)) unlike the regular $2 \mathrm{D}{ }^{1} \mathrm{H} /{ }^{1} \mathrm{H}$ spectrum shown in Fig. 7(b). It is worth noting that due to the suppression of non-carbon-bonded $\mathrm{H} 7$ signals, $\mathrm{H} 5$ and $\mathrm{H} 3$ signals are better resolved in the 2D ${ }^{1} \mathrm{H} /{ }^{1} \mathrm{H}(\mathrm{F} 1 / \mathrm{F} 3)$ correlation spectrum (Fig. 7(a)) as well as their correlation signals with other protons, in contrast to the regular $2 \mathrm{D}{ }^{1} \mathrm{H} /{ }^{1} \mathrm{H}$ spectrum given in Fig. 7(b). In the fpRFDR mediated ${ }^{1} \mathrm{H} /{ }^{13} \mathrm{C}(\mathrm{F} 1 / \mathrm{F} 2)$ correlation spectrum, cross peaks between non-bonded ${ }^{13} \mathrm{C}-{ }^{1} \mathrm{H}$ pairs appear due to the magnetization exchange among protons before the ${ }^{1} \mathrm{H} \rightarrow{ }^{13} \mathrm{C}$ polarization transfer period in the $3 \mathrm{D}$ experiment. In fact, with a $3 \mathrm{~ms}$ fp-RFDR mixing time, the proton-bonded carbons are correlated with all protons (Fig. 7(c)). For example, C3 correlates with all the protons as indicated in Fig. 7(c), because $\mathrm{H} 3$ has magnetization exchange with all the protons through recoupled ${ }^{1} \mathrm{H}-{ }^{1} \mathrm{H}$ dipolar couplings with a $3 \mathrm{~ms}$ fp-RFDR mixing. Indeed, by controlling the magnetization exchange between $\mathrm{H} 3$ and other protons using the fp-RFDR mixing time, the proximity between $\mathrm{H} 3$-bonded $\mathrm{C} 3$ and the other protons can be obtained. The cross peaks between $\mathrm{C} 2$ and other protons are relatively weak in intensity due to the fast $T_{2}$ relaxation as mentioned above.

\section{CONCLUSION}

In this study, the performance of a $3 \mathrm{D}{ }^{1} \mathrm{H} /{ }^{13} \mathrm{C} /{ }^{1} \mathrm{H}$ pulse sequence that correlates the chemical shifts of ${ }^{1} \mathrm{H}$ and ${ }^{13} \mathrm{C}$ nuclei is experimentally demonstrated under ultrafast magicangle-spinning (ultrafast-MAS) conditions. The experimental results demonstrate that the INEPT-based transfer of magnetization between dipolar coupled heteronuclei can be used to enhance spectral resolution by eliminating resonances from non-carbon-bonded protons and non-proton-bonded carbons. Though the dipolar couplings present in rigid solids are used in INEPT, heteronuclear scalar couplings can also be used in 3D experiments on semi-solids, dynamic chemical groups, or heterogeneous mixture containing rigid and mobile solids. By incorporating fp-RFDR to enable magnetization exchange among protons, the 3D RFDR-HSQC sequence can be used to determine the proximities of homonuclear and heteronuclear nuclei. As demonstrated by the experimental results, the combination of the three different $2 \mathrm{D}$ spectra extracted from a single $3 \mathrm{D}$ spectrum enables ${ }^{1} \mathrm{H}-{ }^{1} \mathrm{H}_{-}{ }^{13} \mathrm{C}$ proximities/correlations to be obtained, which would be valuable in the structural studies of solids. Our results also show that a 3D spectrum with a desired extent of spectral resolution and correlation with remote protons can be obtained by appropriately selecting the fp-RFDR mixing time and INEPT delay times. Overall, the proposed proton-detected 3D pulse sequence is easy to set up and can be used to extract abundant information about molecular structures under ultrafast-MAS conditions. We believe that the 3D NMR experiment when combined with proton dilution by deuteration or selective ${ }^{13} \mathrm{C}$ (and/or ${ }^{15} \mathrm{~N}$ ) labeling would be useful to study a variety of chemical and biological solids including proteins.

\section{ACKNOWLEDGMENTS}

This research was supported by funds from NIH (No. GM084018 and GM095640 to A.R.). We would like to thank the technical support from scientists at JEOL RESONANCE, Inc. and help in program troubleshooting from Dr. Vadim Zorin (Agilent) and Dr. David Rice (Stanford University).

${ }^{1}$ K. Schmidt-Rohr and H. W. Spiess, Multidimensional Solid-State NMR and Polymers (Academic Press, London, 1994).

${ }^{2}$ C. Bonhomme, C. Gervais, and D. Laurencin, Prog. Nucl. Magn. Reson. Spectrosc. 77, 1 (2014).

${ }^{3}$ R. K. Harris, J. Pharm. Pharmacol. 59, 225 (2007).

${ }^{4}$ M. Tang, G. Comellas, and C. M. Rienstra, Acc. Chem. Res. 46, 2080 (2013).

${ }^{5}$ M. Hong, Y. Zhang, and F. Hu, Annu. Rev. Phys. Chem. 63, 1 (2012).

${ }^{6}$ R. Tycko, Annu. Rev. Phys. Chem. 62, 279 (2011). 
${ }^{7}$ R. Tycko, Prog. Nucl. Magn. Reson. Spectrosc. 42, 53 (2003).

${ }^{8}$ A. Ramamoorthy, Solid State Nucl. Magn. Reson. 35, 201 (2009).

${ }^{9}$ NMR Spectroscopy of Biological Solids, edited by A. Ramamoorthy (CRC Press, 2010).

${ }^{10}$ T. Fujiwara and A. Ramamoorthy, Annu. Rep. NMR Spectrosc. 58, 155 (2006).

${ }^{11}$ E. K. Paulson, C. R. Morcombe, V. Gaponenko, B. Dancheck, R. A. Byrd, and K. W. Zilm, J. Am. Chem. Soc. 125, 15831 (2003).

${ }^{12}$ L. B. Andreas, T. Le Marchand, K. Jaudzems, and G. Pintacuda, J. Magn. Reson. 253, 36 (2015).

${ }^{13}$ A. Böckmann, M. Ernst, and B. H. Meier, J. Magn. Reson. 253, 71 (2015).

${ }^{14}$ D. H. Zhou, G. Shah, M. Cormos, C. Mullen, D. Sandoz, and C. M. Rienstra, J. Am. Chem. Soc. 129, 11791 (2007).

${ }^{15}$ R. Zhang, J. Damron, T. Vosegaard, and A. Ramamoorthy, J. Magn. Reson. 250, 37 (2015).

${ }^{16}$ R. Zhang and A. Ramamoorthy, J. Chem. Phys. 142, 204201 (2015).

${ }^{17}$ R. Zhang, M. K. Pandey, Y. Nishiyama, and A. Ramamoorthy, Sci. Rep. 5, 11810 (2015)

${ }^{18}$ S. Asami and B. Reif, Acc. Chem. Res. 46, 2089 (2013).

${ }^{19}$ B. Reif, J. Magn. Reson. 216, 1 (2012).

${ }^{20}$ E. Barbet-Massin, A. J. Pell, J. S. Retel, L. B. Andreas, K. Jaudzems, W. T. Franks, A. J. Nieuwkoop, M. Hiller, V. Higman, P. Guerry, A. Bertarello, M. J. Knight, M. Felletti, T. Le Marchand, S. Kotelovica, I. Akopjana, K. Tars, M. Stoppini, V. Bellotti, M. Bolognesi, S. Ricagno, J. J. Chou, R. G. Griffin, H. Oschkinat, A. Lesage, L. Emsley, T. Herrmann, and G. Pintacuda, J. Am. Chem. Soc. 136, 12489 (2014).

${ }^{21}$ M. J. Knight, I. C. Felli, R. Pierattelli, I. Bertini, L. Emsley, T. Herrmann, and G. Pintacuda, J. Am. Chem. Soc. 134, 14730 (2012).

${ }^{22}$ S. M. Althaus, K. Mao, J. A. Stringer, T. Kobayashi, and M. Pruski, Solid State Nucl. Magn. Reson. 57-58, 17 (2013).

${ }^{23}$ Y. Nishiyama, T. Kobayashi, M. Malon, D. Singappuli-Arachchige, I. I. Slowing, and M. Pruski, Solid State Nucl. Magn. Reson. 66-67, 56 (2015).

${ }^{24}$ Y. Nishiyama, M. Malon, M. J. Potrzebowski, P. Paluch, and J. P. Amoureux, "Accurate NMR determination of $\mathrm{C}-\mathrm{H}$ or $\mathrm{N}-\mathrm{H}$ distances for unlabeled molecules," Solid State Nucl. Magn. Reson. (in press).

${ }^{25} \mathrm{M}$. Kotecha, N. P. Wickramasinghe, and Y. Ishii, Magn. Reson. Chem. 45, S221 (2007).

${ }^{26}$ S. Laage, J. R. Sachleben, S. Steuernagel, R. Pierattelli, G. Pintacuda, and L. Emsley, J. Magn. Reson. 196, 133 (2009).

${ }^{27}$ A. Lange, I. Scholz, T. Manolikas, M. Ernst, and B. H. Meier, Chem. Phys. Lett. 468, 100 (2009).

${ }^{28}$ S. Laage, A. Marchetti, J. Sein, R. Pierattelli, H. J. Sass, S. Grzesiek, A. Lesage, G. Pintacuda, and L. Emsley, J. Am. Chem. Soc. 130, 17216 (2008).

${ }^{29}$ V. S. Mithu, S. Paul, N. D. Kurur, and P. K. Madhu, J. Magn. Reson. 209, 359 (2011).
${ }^{30}$ M. Weingarth, G. Bodenhausen, and P. Tekely, J. Magn. Reson. 199, 238 (2009).

${ }^{31}$ M. Ernst, A. Samoson, and B. H. Meier, Chem. Phys. Lett. 348, 293 (2001).

${ }^{32}$ G. A. Morris, J. Am. Chem. Soc. 102, 428 (1980).

${ }^{33}$ D. T. Pegg, D. M. Doddrell, W. M. Brooks, and M. R. Bendall, J. Magn. Reson. 44, 32 (1981).

${ }^{34}$ M. Lee and W. I. Goldburg, Phys. Rev. 140, A1261 (1965).

${ }^{35}$ A. Bielecki, A. C. Kolbert, and M. H. Levitt, Chem. Phys. Lett. 155, 341 (1989).

${ }^{36}$ E. Vinogradov, P. K. Madhu, and S. Vega, Chem. Phys. Lett. 314, 443 (1999).

${ }^{37}$ D. Sakellariou, A. Lesage, P. Hodgkinson, and L. Emsley, Chem. Phys. Lett. 319, 253 (2000).

${ }^{38}$ B. Elena, G. de Paëpe, and L. Emsley, Chem. Phys. Lett. 398, 532 (2004).

${ }^{39}$ K. Mao and M. Pruski, J. Magn. Reson. 201, 165 (2009).

${ }^{40}$ K. Mao and M. Pruski, J. Magn. Reson. 203, 144 (2010).

${ }^{41}$ B. Elena, A. Lesage, S. Steuernagel, A. Böckmann, and L. Emsley, J. Am. Chem. Soc. 127, 17296 (2005).

${ }^{42}$ G. P. Holland, B. R. Cherry, J. E. Jenkins, and J. L. Yarger, J. Magn. Reson. 202, 64 (2010).

${ }^{43}$ R. Zhang and A. Ramamoorthy, J. Magn. Reson. 243, 85 (2014).

${ }^{44}$ Y. Ishii, J. Chem. Phys. 114, 8473 (2001).

${ }^{45}$ Y. Nishiyama, R. Zhang, and A. Ramamoorthy, J. Magn. Reson. 243, 25 (2014).

${ }^{46}$ R. Zhang, Y. Nishiyama, P. Sun, and A. Ramamoorthy, J. Magn. Reson. 252, 55 (2015).

${ }^{47}$ A. E. Bennett, R. G. Griffin, J. H. Ok, and S. Vega, J. Chem. Phys. 96, 8624 (1992).

${ }^{48}$ K. H. Mroue, Y. Nishiyama, M. K. Pandey, B. Gong, E. McNerny, D. H. Kohn, M. D. Morris, and A. Ramamoorthy, Sci. Rep. 5, 11991 (2015).

${ }^{49}$ R. Zhang, M. K. Pandey, Y. Nishiyama, and A. Ramamoorthy, Sci. Rep. 5, 11810 (2015).

${ }^{50}$ Y. Nishiyama, M. Malon, Y. Ishii, and A. Ramamoorthy, J. Magn. Reson. 244, 1 (2014).

${ }^{51}$ S. Parthasarathy, Y. Nishiyama, and Y. Ishii, Acc. Chem. Res. 46, 2127 (2013).

${ }^{52}$ V. E. Zorin, S. P. Brown, and P. Hodgkinson, J. Chem. Phys. 125, 144508 (2006).

${ }^{53}$ E. C. Lin and S. J. Opella, J. Magn. Reson. 239, 57 (2014).

${ }^{54}$ V. Agarwal, S. Penzel, K. Szekely, R. Cadalbert, E. Testori, A. Oss, J. Past, A. Samoson, M. Ernst, A. Böckmann, and B. H. Meier, Angew. Chem., Int. Ed. 53, 12253 (2014).

${ }^{55}$ D. H. Zhou, J. J. Shea, A. J. Nieuwkoop, W. T. Franks, B. J. Wylie, C. Mullen, D. Sandoz, and C. M. Rienstra, Angew. Chem., Int. Ed. 46, 8380 (2007).

${ }^{56}$ R. Zhang and A. Ramamoorthy, J. Chem. Phys. 143, 034201 (2015). 